\title{
Optimal PAR intensity for spring bloom in the Northwest Pacific marginal seas
}

\author{
Cheng Chen ${ }^{\mathrm{a}, \mathrm{b}}$, , Zhihua Mao ${ }^{\mathrm{a}}$, Guoqi Han ${ }^{\mathrm{c}}$, Teng $\mathrm{Li}^{\mathrm{a}}$, Zheng Wang ${ }^{\mathrm{d}, \mathrm{e}}$, Bangyi Tao ${ }^{\mathrm{a}}$, \\ Tianyu Wang ${ }^{\mathrm{a}}$, Fang Gong ${ }^{\mathrm{a}}$ \\ a State Key Laboratory of Satellite Ocean Environment Dynamics, Second Institute of Oceanography, State \\ Oceanic Administration, Hangzhou 310012, China \\ b East China Sea Fisheries Research Institute, Chinese Academy of Fisheries Science, Shanghai 200090, \\ China \\ c Biological and Physical Oceanography Section, Fisheries and Oceans Canada, Northwest Atlantic Fisheries \\ Centre, St. John's, NL, A1C 5X1, Canada \\ d School of Geographic and Oceanographic Sciences, Nanjing University, Nanjing 210023, China \\ e Collaborative Innovation Center for the South China Sea Studies, Nanjing University, Nanjing 210023, \\ China \\ * Corresponding author: Tel.: +86 57181963121; fax: +86 57188071539. \\ E-mail address: frankchen1978@aliyun.com (C. Chen).
}

\begin{abstract}
Using ten years (2003-2012) of satellite Chlorophyll-a data, we report that annual phytoplankton bloom climax in the Northwest Pacific marginal seas $\left(17^{\circ}-58^{\circ} \mathrm{N}\right)$ delays northward at a rate of $22.98 \pm 2.86 \mathrm{~km} \mathrm{day}^{-1}$. The spring bloom is a dominant feature of the phytoplankton seasonal cycle in this region, except for the northern South China Sea, which features a winter bloom. The sea surface hourly Photosynthetically Available Radiation (PAR) intensity averaged over the bloom peak duration is nearly uniform $\left(1.04 \pm 0.10 \mathrm{~W} \mathrm{~m}^{-2} \mathrm{~h}^{-1}\right)$ among the four sub-regions (i.e. the northern South China Sea, the Kuroshio waters, the Sea of Japan and the Sea of Okhotsk), although different algal species in these four distinct ecological provinces could adapt to a much larger change in other environmental parameters (including total daily PAR, day length, sea surface temperature, net surface heat flux, mixed layer depth, wind speed and euphotic depth). The differences of the hourly PAR intensity between the four provinces during their bloom periods are smaller than those during non-bloom seasons. In contrast, an increasing total daily PAR ( $\left.\mathrm{W} \mathrm{m}^{-2} \mathrm{day}^{-1}\right)$, due to the longer day length at higher latitudes, may balance decreasing sea surface temperature and induce algal flowering. Our results point to an optimal hourly light intensity for the annual phytoplankton bloom peak timing in this entire region, which could potentially become an indicator for the requirement of these annual bloom peaks.
\end{abstract}

Keywords: annual phytoplankton bloom; latitudinal variation; optimal light intensity; Northwest Pacific marginal seas 


\section{Introduction}

More than one century ago, Blackman investigated the effects of light intensity and temperature on the rate of phytoplankton growth. At constant temperature, the growing rate varies with irradiance, initially increasing as the irradiance increases. However, at higher irradiance, this relationship no longer holds and the rate reaches a plateau. At constant irradiance, the rate increases with temperature over a limited range, which, however, is seen only at high irradiance levels. At low irradiance, increasing temperature has little influence on the rate of algal growth (Blackman, 1905). So far most of similar studies indicate that there is a maximum algal production rate at optimal light intensity based on laboratory algae culture experiments (Platt et al., 1980; Nicklisch et al., 2008; Winder and Sommer, 2012). However, investigation on how the change of light intensity affects the poleward delay of annual phytoplankton bloom climax is few. Previous studies found that the compensation of solar irradiance during the bloom initiation was roughly uniform in the North Atlantic Ocean when the spring bloom delayed northward (Siegel et al., 2002). Similarly, the vernal bloom did not occur from the Scotian Shelf to Greenland until the mean Photosynthetically Available Radiation (PAR) within the mixed layer reached at least about $15 \mathrm{~W} \mathrm{~m}^{-2} \mathrm{day}^{-1}$. The variation of the mean PAR in the mixed layer was remarkably narrow in this poleward delay of the bloom (Platt et al., 2009; Zhai et al., 2011). Furthermore in an earlier study, Morel suggested that in the summer phytoplankton growing season at high latitudes, the radiation energy at the sea surface is comparable to that experienced at the low latitudes. The depressive effect of low temperature is partly compensated by improved conditions for photosynthesis due to the longer day length (Morel, 1991). Siegel et al. also suggested that sea surface incoming PAR increases to the north due simply to increased day length as the spring bloom progresses northward (Siegel et al., 2002). We note that the PAR used in the aforementioned studies is the total daily PAR. In our opinion, the aforementioned studies have insufficient consideration of the role of the light/PAR intensity in the poleward delay of annual phytoplankton bloom climax.

PAR intensities regulate the range of primary production in the euphotic zone through both photolimitation (light level too low) and photoinhibition (light level too high). The mean PAR in the mixed layer is controlled by three variables: incident PAR at the water surface, mixed layer depth, and diffuse attenuation coefficient (Riley, 1957; Cole et al., 2015). However, the variability of the PAR at the sea surface is probably more important in determining the subsurface light conditions than changes in the water mass attenuation coefficient (Arnone et al., 1998). Recently studies have suggested that the Sverdrup's critical-depth model may not apply because the basic assumption that the plankton is well-mixed in the upper layer is not met (Chiswell, 2011). Instead, the spring bloom forms in the shallow near-surface layers (Cole et al., 2015) and is governed by processes occurring near the surface (Smetacek and Passow, 1990). Further, during the bloom phytoplankton is not necessarily or completely mixed throughout the whole mixed water column (Cole et al., 2015). On the other hand, it is reasonable to assume that fluctuating light levels, because of vertical convection, may allow algal cells to take advantage of periods of higher insolation near the sea surface, and then to compensate for the loss to the photosystem when cells are moved to greater depths thus receiving lower irradiance (Marra, 1978).

In this study we investigate the timing of annual phytoplankton bloom peak in the Northwest Pacific marginal seas. We analyze variability of the total daily PAR, day length and hourly PAR intensity and how they are distributed regionally and 
temporally. Although the study focuses on the Northwest Pacific marginal seas, including the South China Sea (SCS), the Kuroshio waters, the Sea of Japan and the Sea of Okhotsk (Fig. 1), it makes a comparison with similar studies in the North Atlantic. This study aims to show a latitudinal delay of the annual phytoplankton bloom in the Northwest Pacific marginal seas and to identify and explain a potential basin-wide optimum of hourly PAR intensity in the latitudinal delay. The PAR optimum has two attributes: (1) associated with annual bloom peak and (2) nearly uniform basin-wide. Note that our study does not consider nutrient supply, grazing and other losses, which may become critical factors at the end of bloom (Nicklisch et al., 2008).

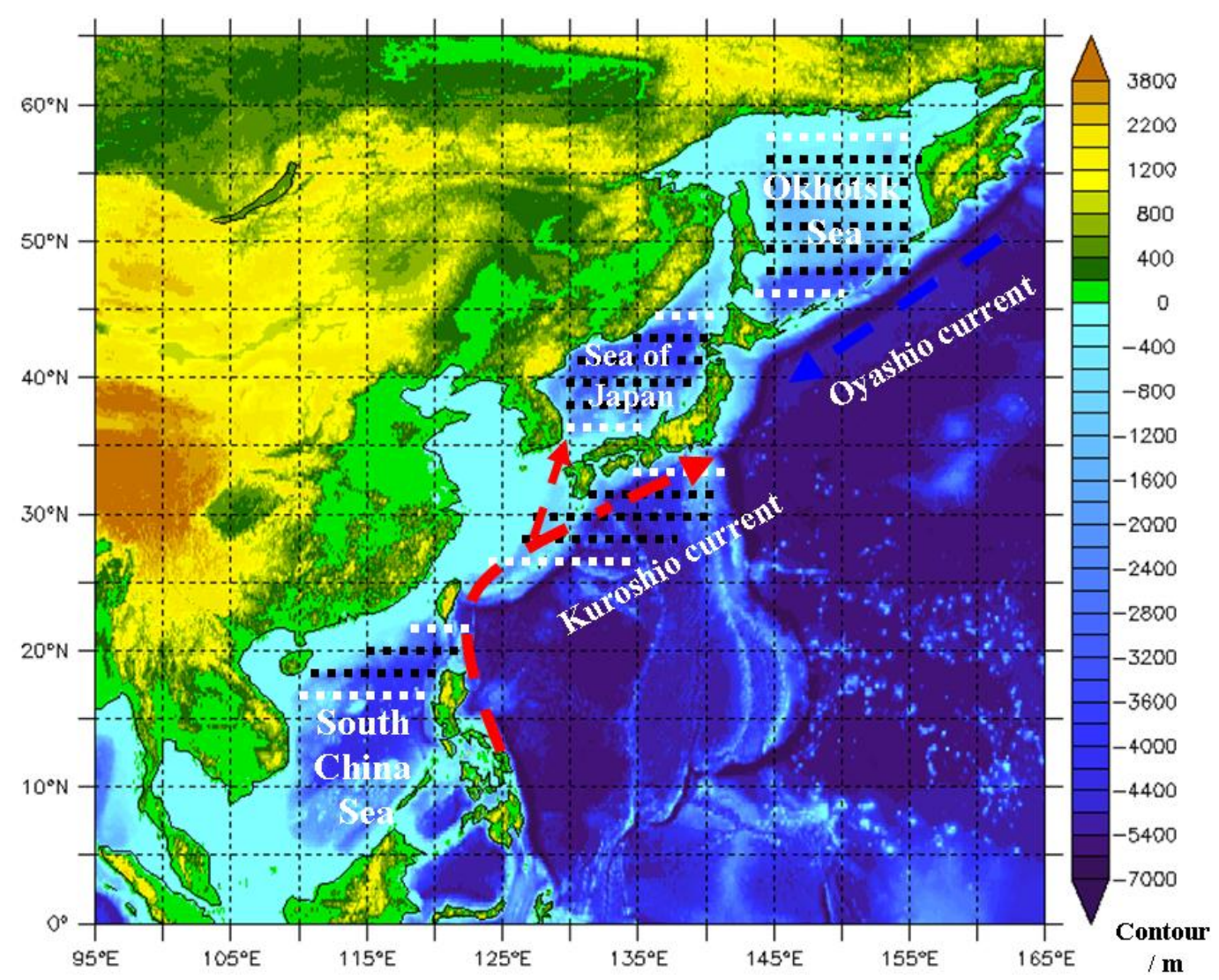

Fig. 1. Study domain for the Northwest Pacific marginal seas, indicated by dashed line, including four sub-bioclimatic regimes from $17^{\circ}$ to $58^{\circ} \mathrm{N}$, i.e. the tropical northern South China Sea $\left(17^{\circ}-22^{\circ} \mathrm{N}\right)$, subtropical Kurshio waters $\left(28^{\circ}-33^{\circ} \mathrm{N}\right)$, temperate Sea of Japan $\left(36^{\circ}-46^{\circ} \mathrm{N}\right)$, and sub-polar Okhotsk Sea $\left(47^{\circ}-58^{\circ} \mathrm{N}\right)$. The topography is based on the ETOPO5 Global Surface Relief product (http://apdrc.soest.hawaii.edu/).

\section{Data and Methods}

\subsection{Satellite data}

We use the MODerate resolution Imaging Spectroradiometer (MODIS)-Aqua Chlorophyll-a concentration (Chl-a) level-3 product (OC3M algorithm), which is used as a proxy for marine phytoplankton biomass. MODIS-derived other oceanic products are also used, included PAR, sea surface temperature (SST, daytime) and euphotic depth. PAR is defined as the quantum energy flux from the sun in the spectral range of 
400-700 nm, which is an estimate of daily-averaged, cloudiness-corrected, incident photosynthetically active solar irradiance reaching the ocean surface (Frouin and Pinker, 1995). MODIS-Aqua 8-day composite Chl-a, PAR, euphotic depth and SST data all gridded to a $4 \mathrm{~km} \times 4 \mathrm{~km}$ resolution from January $1^{\text {st }} 2003$ to December $31^{\text {st }} 2012$ (no missing data within studied bloom seasons) were downloaded from the NASA/Goddard Earth Science Data and Information Services Center Interactive Online Visualization and Analysis System. Hourly PAR was then calculated by dividing daily PAR by day length. Other source data include day length (DL), net surface heat flux, Mixed Layer Depth (MLD) and wind speed (the source of these data see in Table 1). All data extracted on a $1^{\circ}$ latitudinal band is used to investigate latitudinal variability (Fig. 1). On the other hand, for the comparison of bloom conditions between the four sub-regions (the three marginal seas and the Kuroshio waters), regional averages of the environmental variables are considered to minimize the influence of advection on the observed bloom periods, while maintaining the ability to address the spatial variability in the seasonal properties of the phytoplankton (Behrenfeld, 2010). The MODIS Chl-a has an accuracy of $\pm 35 \%$ in the open ocean (bottom depth $>200 \mathrm{~m}$ ), set by community consensus (McClain and Meister, 2012). Observations from shallow waters $(<200 \mathrm{~m})$ are not included due to potential data contamination (Fig. 1). Moreover, the effect of non-biogenetic pigments effect is relatively small during peak timing of algal blooms.

\subsection{Definition of bioclimatic sub-regions}

The studied Northwest Pacific marginal seas $\left(17^{\circ}-58^{\circ} \mathrm{N}\right.$, but not continuous) are divided into four bioclimatic regimes, namely, the Tropical Zone $\left(17^{\circ}-22^{\circ} \mathrm{N}\right.$, mainly in the northern South China Sea, hereafter SCS), the Subtropical Zone $\left(28^{\circ}-33^{\circ} \mathrm{N}\right.$, the Kuroshio waters) and the Temperate Zone $\left(36^{\circ}-46^{\circ} \mathrm{N}\right.$, the Sea of Japan), and the subpolar Zone $\left(47^{\circ}-58^{\circ} \mathrm{N}\right.$, the Sea of Okhotsk). This dividing is mainly based upon both the geographical setting and the bio-physical features, and is consistent with previous studies on Large Marine Ecosystems of the world (Sherman and Hempel, 2009). These sub-regions are strongly influenced by and linked through the large-scale circulation of major water masses (warm/salty Kuroshio waters and cold/fresh Oyashio waters, Fig. 1). Our definition of the SCS boundary is consistent with field observations of the winter bloom (Zhai et al., 2011; Shang et al., 2012). Current remotely sensed observations show no evident phytoplankton seasonality in the SCS south of $17^{\circ} \mathrm{N}$. The offshore boundary of the Kuroshio waters in the present study is determined from the strength of the seasonal Chl-a signal. Southeast of this boundary is the typical subtropical, oligotrophic region where the Chl-a concentration is low and has almost no detectable seasonal cycle $\left(<0.1 \mathrm{mg} \mathrm{m}^{-3}\right.$ year round). The timing of the bloom north of $58^{\circ} \mathrm{N}$ in the Northern Pacific is earlier than what is expected according to latitude alone, probably in part because of the strong influence of the annual melting of sea ice similar to the situation in the North Atlantic (Siegel et al., 2002; Koeller et al., 2009). 
Table 1 (a) Field measurements of predominant phytoplankton species and averaged Chl-a concentrations in the algal bloom in our studied bins collected from previous studies. (b) Regionally-averaged statistics characterizing the latitudinal delay of the bloom, included median statistics (2003-2012) for the date of the bloom peak (YDpeak) and the climatological estimates (decadal mean \pm SD) of the averaged variation on the defined bloom peak timing on seven environmental parameters: total daily PAR, Day length, SST, Net surface heat flux, MLD, Wind speed and Euphotic depth. (c) Comparison of the variability of the total daily PAR, Day length (DL) and hourly PAR intensity $\left(\mathrm{W} \mathrm{m}^{-2} \mathrm{~h}^{-1}\right)$ for the bloom season (bold) and other non-bloom season before and after.

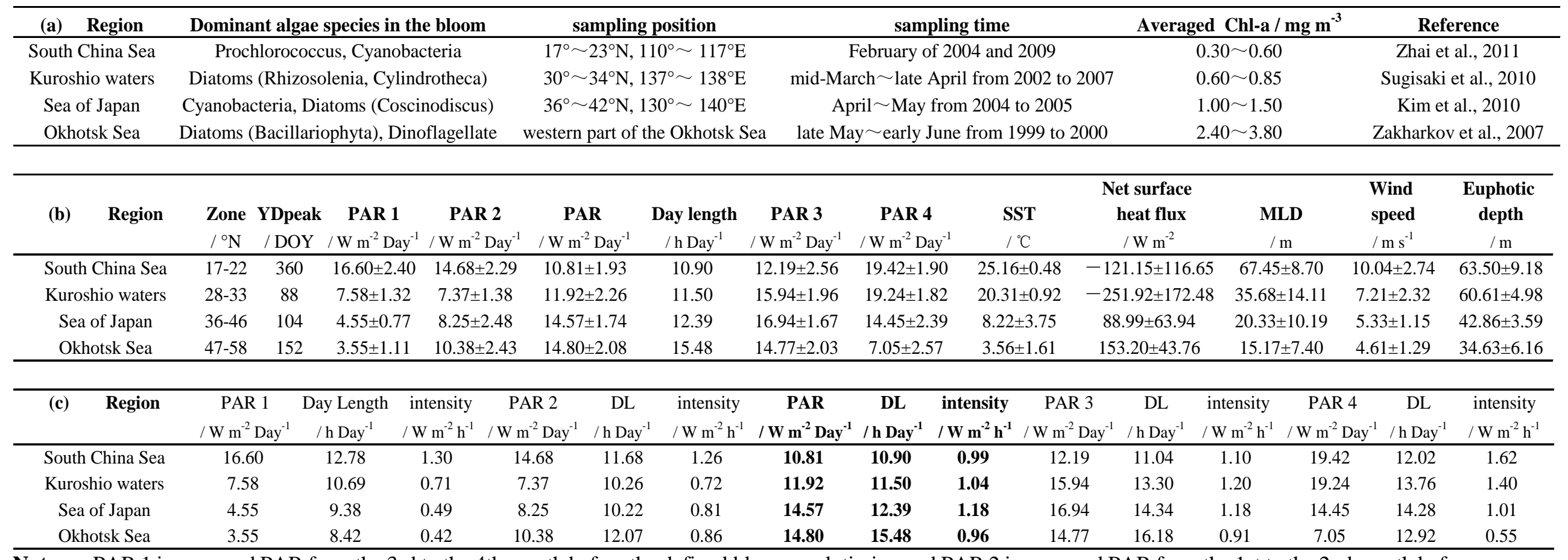

Notes: PAR 1 is averaged PAR from the 3rd to the 4 th month before the defined bloom peak timing and PAR 2 is averaged PAR from the 1 st to the 2 nd month before the bloom season. PAR 3 is averaged PAR from the 1st to the 2nd month after the bloom season and PAR 4 is averaged PAR from the 3rd to the 4th month after the period. Climatological estimates of the monthly mean MLD are derived from the NODC World Ocean Atlas 2013 and weekly wind speed data are derived from QuikSCAT Winds (2003-2009). Daily net ocean surface heat flux comes from the Woods Hole Oceanographic Institute's OAFlux dataset (2003-2009), positive values indicating net surface heat flux downward from air to sea. Day length data estimates are based on Jean (1999) Astronomical algorithms (http://www.orchidculture.com/COD/daylength.html). 


\subsection{Determination of the annual phytoplankton bloom peak timing}

To set the threshold for the spring bloom, the first index is simply the timing of the annual maximum. The timing is defined as the date on which the surface Chl-a concentration reached its maximum value in each year (Siegel et al., 2002). This definition provides a relative, but not absolute, Chl-a level to help build a comparable method that works for different biogeochemical zone in terms of different bloom magnitude (Ferreira et al., 2014). Spring blooms are dominant features of the phytoplankton cycle in these sub-regions with secondary weaker fall peak, except for the SCS which features a dominant winter bloom. The 8-day resolution Chl-a data matches the time scale of typical algal bloom processes ( $\sim$ a week), so the date and magnitude of the annual peak found in the Chl-a data are acceptable proxies for annual maximum phytoplankton bloom events. Latitudinal variation is defined by the latitudinal change of the time when the annual Chl-a peak occurs. Instead of fitting a Gaussian distribution to the bloom (Platt et al., 2009), peak timing is obtained directly from the decadal median of the Chl-a seasonal variability (Fig. 2). The decadal median (2003-2012) of Chl-a is calculated from the mean of the two middle numbers in decadal time series. The impact of rare large outliers in the Chl-a time series on the accuracy of the timing of the bloom peak timing is investigated by comparing between the decadal median and arithmetically averaged Chl-a time series. It is found that $90 \%$ of the differences in peak timing caused by large outliers are no more than 16 days, which has no significant influence on this basin-scale estimation (Table 1).

Furthermore the median results are used to minimize the influence of rare large outliers (Siegel et al., 2002). We recognize that a robust definition of the bloom onset time remains an issue of debate. Generally, the tropics and subtropics present long phytoplankton growing period $(\approx 15-20$ weeks $)$ of low amplitude, whereas the high-latitudes show short growing period $(<10$ weeks) of high amplitude (Racault et al., 2012). Finally, we define a typical phytoplankton growing season (i.e. annual phytoplankton bloom peak timing) to be about two months ( $\approx 9$ weeks), from 32 days before the annual Chl-a climax date to 32 days after, considering the interannual variability of the peak date (Fig. 3) and the 8-day temporal resolution of the satellite data. We recognize that this definition has large uncertainty in the SCS only based on satellite observation. But the SCS pelagic ecosystem responds to the strong seasonality of the monsoon winds and has winter phytoplankton blooms (peak timing occurs from December to January generally), which is verified by several previous field observations (Zhai et al., 2011; Shang et al., 2012; Longhurst, 1995; Tang et al., 1999). 


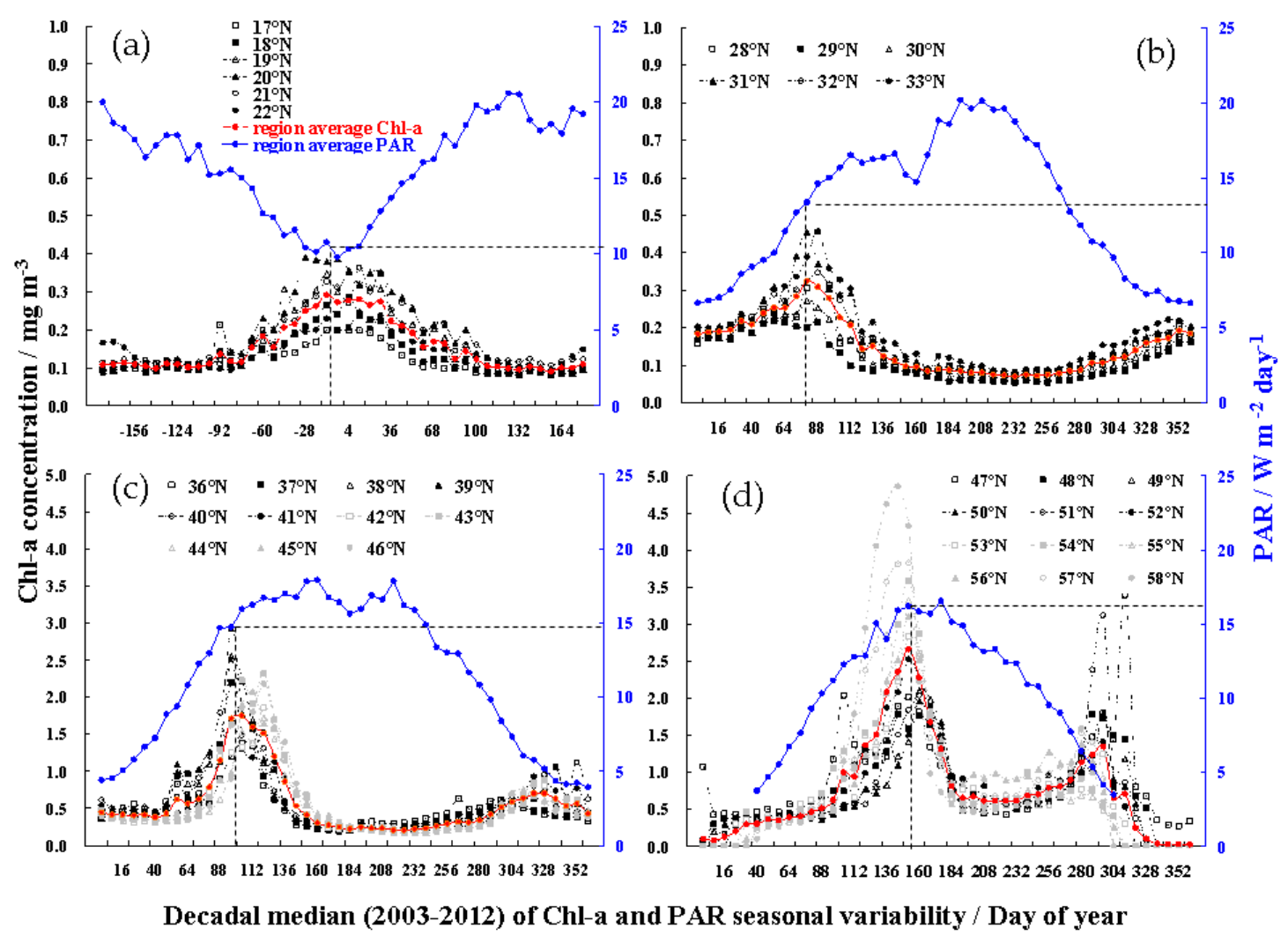

Fig. 2. Decadal median seasonality of Chl-a (each latitudinal values (black lines) and regional averaged (red line)) and PAR (regional averaged, blue line) for each sub-domain: (a) South China Sea, (b) Kurshio waters, (c) Sea of Japan and (d) Okhotsk Sea, respectively. The regional averaged peak Chl-a timing and corresponding PAR values are marked with dashed lines. Day zero indicates Jan $1^{\text {st }}$ in the calendar year, and day -180 means Jul $1^{\text {st }}$ in the previous year.

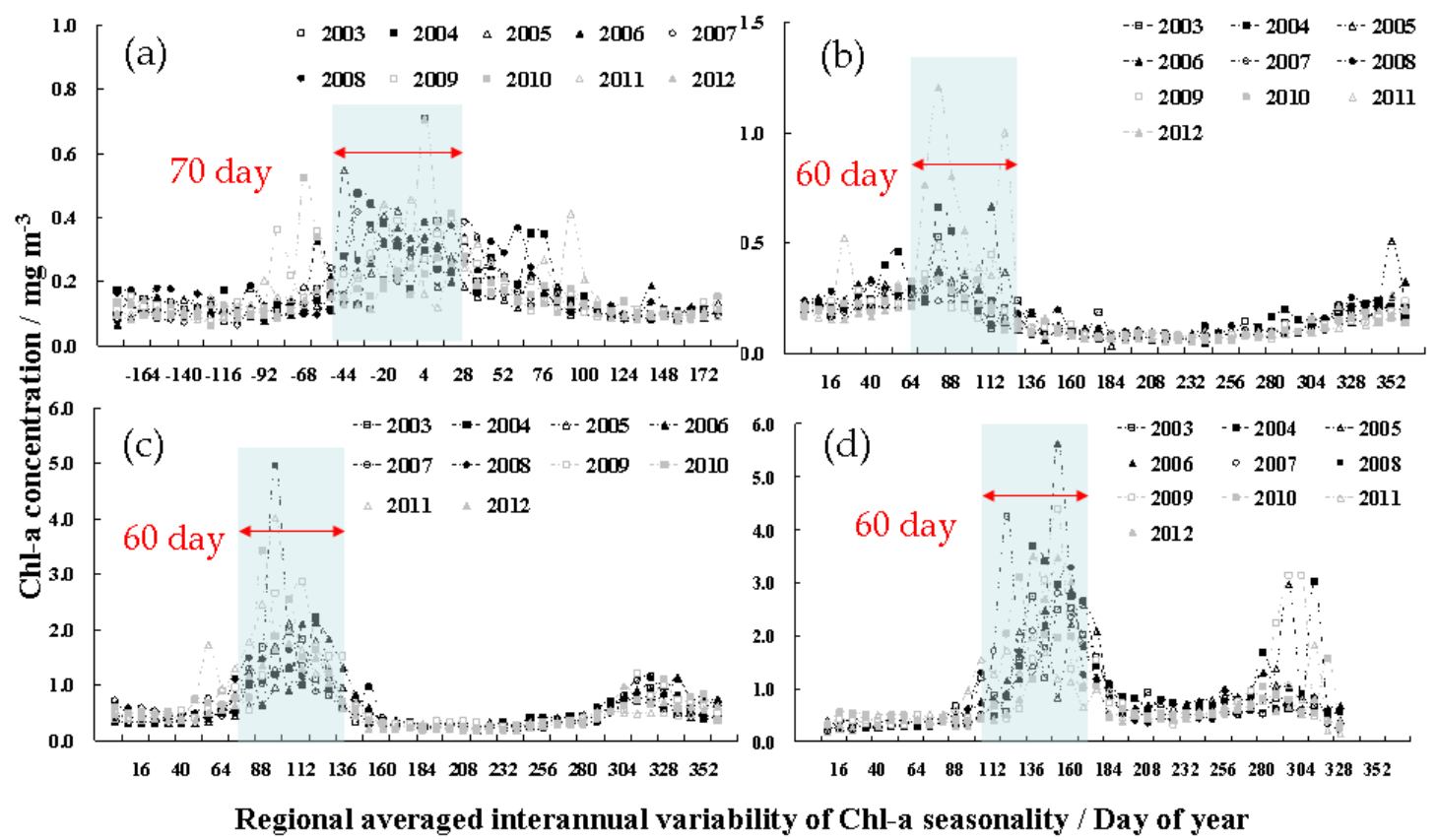

Fig. 3. Regional averaged interannual variability (2003-2012) of Chl-a seasonality is shown as (a) South China Sea, (b) Kurshio waters, (c) Sea of Japan and (d) Okhotsk Sea, respectively. The blue shade indicates the range of interannual change of annual peak Chl-a timing. 


\section{Results}

\subsection{Latitudinal delay of the spring bloom}

The time of the annual peak in the bloom, as measured by the decadal median (2003-2012, the definition of the decadal median in the section of 2.3), is similar from year-to-year within each sub-region, but differs between any two sub-regions (Fig. 2 and Fig. 3). This time series of the $1^{\circ}$ averaged Chl-a clearly shows that the peak timing varies with latitude. Combining these four sub-regions together, we estimate that the northward delay of the bloom propagates at a rate of $22.98 \pm 2.86 \mathrm{~km}^{\text {day }}{ }^{-1}$ (decadal median \pm standard deviation (SD)). The slope $\left({ }^{\circ}\right.$ day $\left.^{-1}\right)$ of the linear regression equation (solid black line, $\mathrm{y}=0.207 \mathrm{x}+18.757, \mathrm{R}^{2}=0.88, \mathrm{p}<0.001, \mathrm{n}=37$, Student's t-test, Fig. $4(\mathrm{~b}))$ is used to calculate the rate $\left(0.207^{\circ}\right.$ day $^{-1} \times 111 \mathrm{~km} /{ }^{\circ}=22.98 \mathrm{~km}$ day $\left.^{-1}\right)$. The interannual change in the speed shows no significant trend from 2003 to $2012\left(R^{2}=0.03\right.$, $\mathrm{p}=0.63, \mathrm{n}=10$ ). In general, our results agree with those from previous field studies (Zhai et al., 2011; Shang et al., 2012; Longhurst, 1995; Tang et al., 1999; Hama et al., 1997; Sugisaki et al., 2010; Yamada et al., 2005; Kim, 2012). These field studies identified seasonal cycles of the phytoplankton blooms for each of the above mentioned sub-regions. Here, we applied satellite data to show the spatial connection in the seasonal timing of the bloom between these sub-domains.

\subsection{PAR over the spring bloom period}

We further analyze the PAR and SST averaged over the defined bloom peak timing in this latitudinal variation based on the ten-year data (total sample size $=35$ latitudinal bands $\times 10$ year $=350$, Fig. 4(a)). The relationship between the two parameters indicates that even a slight increase in solar irradiance can play a key role in the lower temperature acclimation for algae flowering at higher latitude (Morel, 1991). This relationship also shows a balance and compensation mechanism exists between light and temperature interaction in algal growth. Furthermore, in this balance process the range of the temperature niche (about $0 \sim 30^{\circ} \mathrm{C}$ ) is much larger than that of irradiance niche (about $8 \sim 18 \mathrm{~W} \mathrm{~m}^{-2}$ day $^{-1}$, Fig. 4(a)). In other words, the poleward delay of bloom appears to be limited more by solar insolation (PAR) than by temperature (SST). A more complete climatological estimation of the effects of 8 environmental parameters (i.e., total daily PAR, day length, hourly PAR intensity, SST, Net surface heat flux, MLD, Wind speed and Euphotic depth) over the bloom peak timing is shown in Table $1(b-c)$. Then comparison of the range of variation of these different environmental parameters in four sub-regions is shown in Table 2. These results suggest that the hourly PAR intensity is more uniform(| SD / Mean| $\times 100 \%=9 \%$ and $\mid$ (max. - min.) $/$ Mean $\mid \times 100 \%=21 \%$, these two index are considered to remove the effect of different units in different parameters) throughout the northward propagation of the bloom than the other parameters.

The variation in the averaged hourly PAR intensities over the bloom season and their regional differences are relatively small compared with the variation and difference in non-bloom seasons (Table 1 (c)). For example, the averaged hourly PAR intensities are 0.99 and $0.96 \mathrm{~W} \mathrm{~m}^{-2} \mathrm{~h}^{-1}$ in the SCS and the Sea of Okhotsk, respectively, whereas due to significant difference of day length $\left(10.90\right.$ and $\left.15.48 \mathrm{~h} \mathrm{Day}^{-1}\right)$ the total daily PAR for these two regions is 10.81 and $14.80 \mathrm{~W} \mathrm{~m}^{-2} \mathrm{Day}^{-1}$ in this latitudinal progression, respectively. Furthermore the annual anomaly of the PAR intensity over the bloom season is defined as the annual minus the decadal mean over 2003-2012. These anomalies do not vary greatly from year to year $\left( \pm 0.20 \mathrm{~W} \mathrm{~m}^{-2} \mathrm{~h}^{-1}\right.$, Fig. $\left.4(\mathrm{~b})\right)$ when 
compared with the average annual cycle (about $0.42 \sim 1.62 \mathrm{~W} \mathrm{~m}^{-2} \mathrm{~h}^{-1}$, Table 1 (c)) in all four sub-regions.
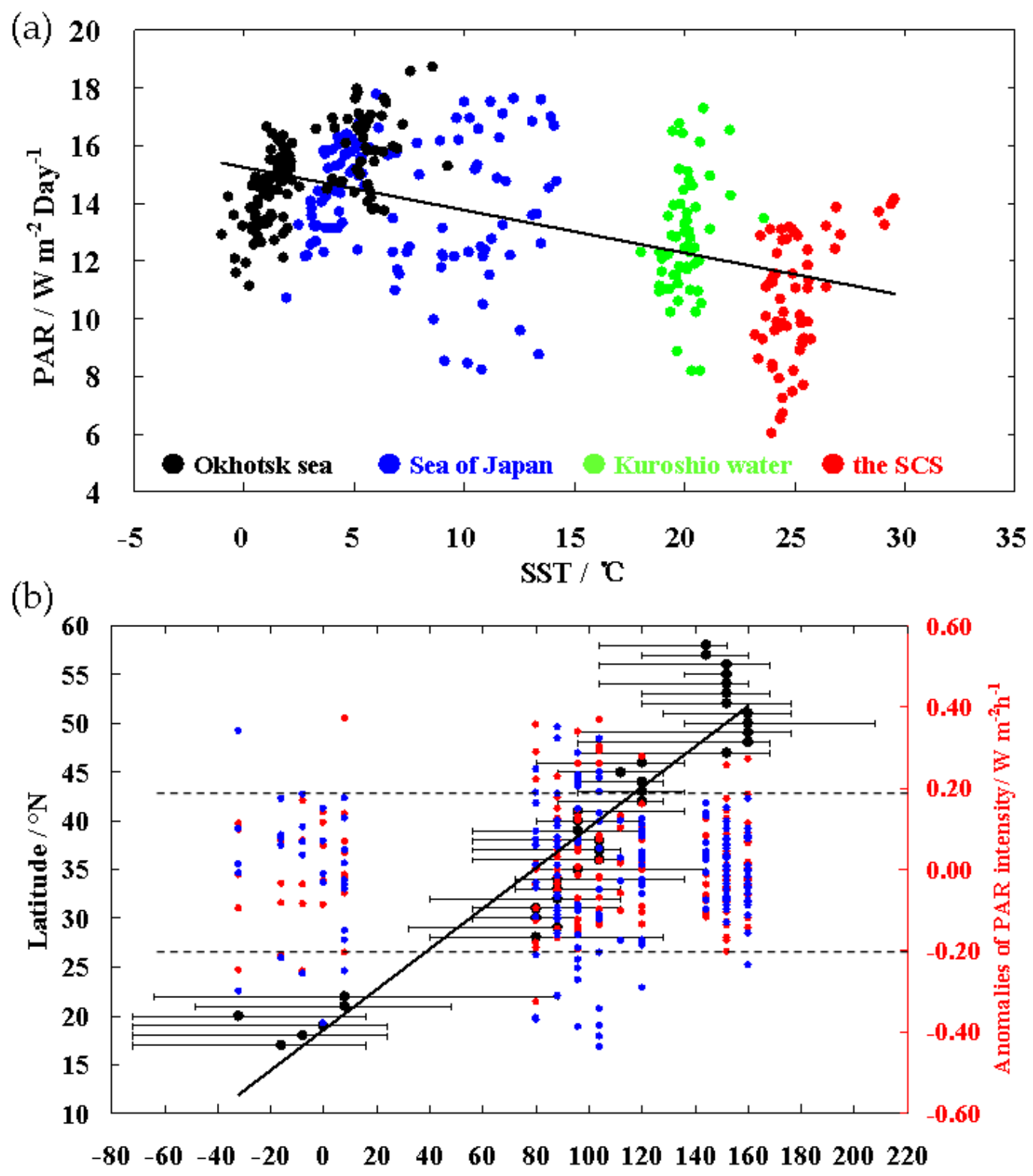

Annual peak timing of Chl-a / Day of year

Fig. 4. (a) Averaged daily PAR versus SST over the bloom peak timing in each sub-domain (every latitude, $n=35$ latitudinal bands $\times 10$ year $=350$ ) from the Okhotsk Sea to the South China Sea from 2003 to 2012. (b) The annual anomalies of the averaged hourly PAR intensity during the bloom peak timing in every $1^{\circ}$ latitudinal band and each year are shown throughout the latitudinal propagation (solid black line). The first pentad (2003-2007) and the second pentad (2008-2012) are marked red and blue circles, respectively. The horizontal bars show the range of the annual variability of bloom peak timing and their decadal medians (solid black circles). 
Table 2 Comparison of the range of variation of different environmental parameters at the bloom peak timing in four sub-regions

\begin{tabular}{|c|c|c|c|c|c|c|c|c|}
\hline Region & $\begin{array}{c}\text { total daily } \\
\text { PAR } \\
\text { / } \mathrm{W} \mathrm{m}^{-2} \mathrm{Day}^{-1} \\
\end{array}$ & $\begin{array}{c}\text { DL } \\
/ \text { h Day }^{-1}\end{array}$ & $\begin{array}{c}\text { hourly PAR } \\
\text { intensity } \\
/ \mathrm{W} \mathrm{m}^{-2} \mathrm{~h}^{-1} \\
\end{array}$ & $\begin{array}{l}\text { SST } \\
/{ }^{\circ} \mathrm{C} \\
\end{array}$ & $\begin{array}{c}\text { Net surface } \\
\text { heat flux } \\
/ \mathrm{W} \mathrm{m}^{-2} \\
\end{array}$ & $\begin{array}{c}\text { MLD } \\
/ \mathrm{m} \\
\end{array}$ & $\begin{array}{l}\text { Wind } \\
\text { speed } \\
/ \mathrm{m} \mathrm{s}^{-1} \\
\end{array}$ & $\begin{array}{c}\text { Euphotic } \\
\text { depth } \\
/ \mathrm{m}\end{array}$ \\
\hline South China Sea & 10.81 & 10.90 & 0.99 & 25.16 & -121.15 & 67.45 & 10.04 & 63.50 \\
\hline Kuroshio waters & 11.92 & 11.50 & 1.04 & 20.31 & -251.92 & 35.68 & 7.21 & 60.61 \\
\hline Sea of Japan & 14.57 & 12.39 & 1.18 & 8.22 & 88.99 & 20.33 & 5.33 & 42.86 \\
\hline Okhotsk Sea & 14.80 & 15.48 & 0.96 & 3.56 & 153.20 & 15.17 & 4.61 & 34.63 \\
\hline Mean & 13.03 & 12.57 & 1.04 & 14.31 & -186.54 & 34.66 & 6.80 & 50.40 \\
\hline Standard Deviation (SD) & 1.97 & 2.04 & 0.10 & 10.11 & 92.47 & 23.53 & 2.42 & 13.92 \\
\hline | SD / Mean $\mid \times 100 \%$ & $15 \%$ & $16 \%$ & $9 \%$ & $71 \%$ & $50 \%$ & $68 \%$ & $36 \%$ & $28 \%$ \\
\hline $\mid(\max .-\min$.$) / Mean \mid \times 100 \%$ & $31 \%$ & $36 \%$ & $21 \%$ & $151 \%$ & $217 \%$ & $151 \%$ & $80 \%$ & $57 \%$ \\
\hline
\end{tabular}

To summarize, hourly PAR intensity over the duration of the bloom does not change significantly with latitude, and it is the most uniform of all environmental parameters between low and high latitudes (Table 2). These findings indicate that there may be an optimal PAR intensity for the annual phytoplankton bloom in the Northwest Pacific, although different algal species present in these distinct ecological provinces (Table 1(a)) could adapt to a much larger change in other environmental parameters.

\section{Discussion}

In an earlier study, Morel suggested that in the summer phytoplankton growing season at high latitudes, the radiation energy at the sea surface is comparable to, or even exceeds, that experienced at the low latitudes. The depressive effect of low temperature is partly compensated by improved conditions for photosynthesis due to the longer day length (Morel, 1991). According to our results, if solar heat energy input only is considered, the increasing daily PAR cannot compensate for the loss of SST. For example, a simple calculation shows that the observed increase in the total daily PAR would raise the temperature of the upper $1 \mathrm{~m}$ of water less than $0.5^{\circ}$ Cover the time period it takes for the bloom peak to propagate from the South China Sea to the Okhotsk Sea. Table 1(b) also suggests that the net surface heat flux exchange between the air and sea has significant differences over the latitudinal extent of the domain. For instance, the net surface heat flux is $-121.15 \pm 116.65 \mathrm{~W} \mathrm{~m}^{-2}$ in the SCS (negative value indicating heat flux upward from sea to air) while it is $153.20 \pm 43.76$ $\mathrm{W} \mathrm{m}{ }^{-2}$ in the Okhotsk Sea. The standard deviation (SD) is due to the interannual variability. It is interesting to note that recent studies in the sub-polar North Atlantic hypothesized that the surface concentration of phytoplankton increases rapidly when atmospheric cooling of the ocean switches over to atmospheric heating at the end of winter (Taylor and Ferrari, 2011; Ferrari et al., 2015) based on the analysis of satellite Chl-a and of air-sea heat flux as used in our study. However, the above hypothesis that the timing of the shift from sea surface cooling to heating is a robust indicator of surface blooms does not explain the significant difference of the net surface heat flux over the bloom period in our study region. There are much larger regional differences in SST and wind speed between our studied sub-regions, which may cause the differences in net surface heat flux (Table 1(b)). It appears that a pure heat condition at air-sea surface alone may not explain the poleward propagation of the bloom peak in our region. Instead, the optimal hourly PAR intensity shown in the present study could potentially become an indicator of surface blooms, because it values during the 
annual boom periods shows small variations across latitude from subtropical to subpolar regions. However, we are unclear if this optimal light intensity is a requirement by physiology or a mere coincidence.

We fully recognize that the PAR intensity niche is not the only factor that affects the initiation of phytoplankton bloom, especially at a local scale. In the South China Sea as some tropical waters local algal bloom may respond to wind or upwelling driven nutrient supply. But a 6-month phase shift in the timing of maximum phytoplankton concentration between subpolar (spring-summer peak) and subtropical (autumn-winter peak) regions had been reported in previous studies (Yoder and Kennelly, 2003; Kahru et al., 2011). Different ecological hypotheses often depend on different spatial-temporal scales, so our results are not inconsistent with previous studies suggesting that phytoplankton could have evolved strategies for coping with the rapid and day-to-day changes in actual light fields (Long et al., 1994). Because from a view of annual production cycle, the phytoplankton growing season (e.g. bloom peak timing) need an optimum and durative environmental niche, such as the optimal averaged PAR intensity during bloom peak timing, to avoid photoinhibition or photolimitation (Fig. 5). In the most of tropical and subtropical oceans a diurnal thermocline of $2-5 \mathrm{~m}$ depth forms during the day. Algae cells trapped in the thermocline have no refuge from full sunlight for the day, and all measures of photosynthesis infer marked photoinhibition (Long et al., 1994). In many temperate oceans the decrease in the intensity of the bloom in summer appears to result from nutrient limitation and perhaps photoinhibition in surface waters (Arnone et al., 1998), whereas photolimitation is the dominating factor to algal growth in the most of polar seas during most of time every year.

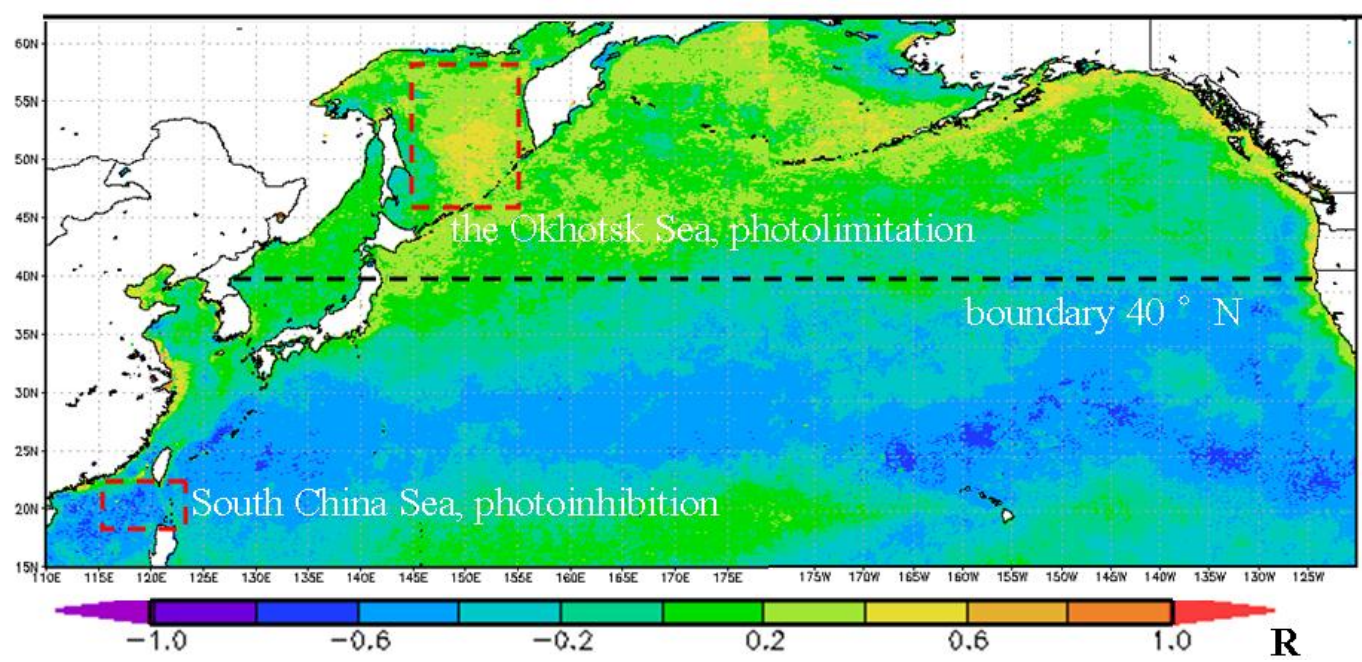

Fig. 5. Spatial distribution of the Pearson correlation coefficient (R) between Chl-a and PAR from ten-year statistics (2003-2012) in the Northern Pacific Ocean. A boundary of $40^{\circ} \mathrm{N}$ divides multi-year phtolimitation (positive correlation between Chl-a and PAR) and photoinhibition (negative correlation between Chl-a and PAR) region.

We also recognize that the timing of the surface bloom peak is influenced by how fast zooplankton grazing or how fast algal cell sinking. But the interannual variability of the peak timing suggests that the fluctuating range of annual maximum bloom date is relatively stable (about 60 day) (Fig. 3), which also implies a stable growing season. The mean PAR in the mixed layer is controlled by three variables: incident PAR at the water surface, mixed layer depth and diffuse attenuation coefficient (Riley, 1957; Cole 
et al., 2015), but consideration of the difficulty of assessing reliable mixed layer depth at the appropriate time resolution(Platt et al., 2009) and absence sufficient field data, we only investigate the variability of sea surface incoming PAR in the latitudinal delay of the bloom in this study. We suggest this setting do not effect our aim to identify and explain a potential environmental optimum in the latitudinal progression. Previous studies had already suggested that the mean PAR or the compensation irradiance in the mixed layer was roughly uniform in the spring bloom northward advancing (Siegel et al., 2002; Platt et al., 2009; Zhai et al., 2011).

It is worth pointing out why we chose to study the Northwest Pacific marginal seas and to compare our results with those in the North Atlantic. Although such seasonal changes in the light niche always occur in other parts of the Pacific and the Southern Ocean, until recently most observations indicated a relatively low sea surface Chl-a pigment concentration in most of these areas throughout the year (Cole et al., 2015; Obata et al., 1996) possibly due to nutrient limitation or an iron constraint. As a whole, the Southern Ocean is a high-nitrate low-chlorophyll region. Its Atlantic section has higher Chl-a and a more notable seasonal variation than its Pacific section. It can reasonably be assumed that the Pacific section, being farther away from continental land masses than the Atlantic section has potentially a lower iron supply to the surface waters. Winter overturning can supply nutrients to the surface water (in particular iron) to support the seasonal increase in phytoplankton growth, but only in spring when light levels are sufficient. The Chl-a at the sea surface generally responds to the seasonal cycle of solar radiation, which strongly impacts vertical stability through net heat flux, which in turn influences the vertical nutrient supply and the timing and intensity of phytoplankton blooms in the South Atlantic (Thomalla et al., 2011).

\section{Conclusions}

We have used ten years (2003-2012) of satellite Chlorophyll-a data to show that annual phytoplankton bloom climax in the Northwest Pacific marginal seas $\left(17^{\circ}-58^{\circ} \mathrm{N}\right)$ delays northward at a rate of $22.98 \pm 2.86 \mathrm{~km}^{\text {day }}{ }^{-1}$. The sea surface hourly PAR intensity averaged over the bloom duration is nearly uniform $\left(1.04 \pm 0.10 \mathrm{~W} \mathrm{~m}^{-2} \mathrm{~h}^{-1}\right)$ among the four sub-regions, while other environmental parameters have much larger change. The hourly PAR intensity has smaller differences between the four provinces during bloom periods than during non-bloom seasons. Therefore, there may be an optimal hourly PAR intensity for the annual phytoplankton bloom peak timing. The optimal PAR intensity may potentially become an indicator for the annual phytoplankton bloom climax in the four different subregions of the Northwest Pacific marginal seas.

\section{Acknowledgments}

Analyses and visualizations used in this study were the Giovanni online data system, developed and maintained by the NASA/GES/DISC. We also acknowledge NASA personnel and associated scientists for producing the MODIS data. This work is supported all by the scientific research fund of the Second Institute of Oceanography, SOA, China (JG1417), and is supported partially by the Public Science and Technology Research Funds Projects of Ocean (201005030), the National Science Foundation of China (41476156, 41321004) and the Special Fund for Agroscientific 
Research in the Public Interest (201303047). We have many thanks for warming discussion, comments and kindness help from Dr. Zuojun Yu, Dr. Daji Huang, Prof. Dongping Wang, Dr. Qiang Hao, Dr. Xinfeng Dai, Dr. Weijia Fan, Prof. Chen-Tung Arthur Chen and Prof. Cho-Teng Liu for the preparation of the paper for more than two years.

\section{References}

Arnone, R. A., Ladner, S., Violette, P. E. L., Brock, J. C., Rochford, P. A., 1998. Seasonal and interannual variability of surface photosynthetically available radiation in the Arabian Sea. Journal of Geophysical Research-Oceans 103, 7735-7748, doi: 10.1029/97JC03204.

Behrenfeld, M. J., 2010. Abandoning Sverdrup's Critical Depth Hypothesis on phytoplankton blooms. Ecology 91, 977-989, doi: 10.1890/09-1207.1.

Blackman, F. F., 1905. Optima and limiting factors. Annals of Botany 19, 281-296.

Chiswell, S. M., 2011. Annual cycles and spring blooms in phytoplankton: don't abandon Sverdrup completely. Marine ecology progress series 443, 39-50, doi: 10.3354/meps09453.

Cloern, J. E., 1996. Phytoplankton bloom dynamics in coastal ecosystems: A review with some general lessons from sustained investigation of San Francisco Bay, California. Reviews of geophysics 34, 127-168, doi: 10.1029/96RG00986.

Cole, H. S., Henson, S., Martin, A. P., Yool, A., 2015. Basin-wide mechanisms for spring bloom initiation: how typical is the North Atlantic? ICES Journal of Marine Science 72, 2029- 2040, doi:10.1093/icesjms/fsu239.

Ferrari, R., Merrifield, S. T., Taylor, J. R., 2015. Shutdown of convection triggers increase of surface chlorophyll. Journal of Marine Systems 147, 116-122, doi: 10.1016/j.jmarsys.2014.02.009.

Ferreira, S., Visser, A. W., MacKenzie, B. R., Payne, M. R., 2014. Accuracy and precision in the calculation of phenology metrics. Journal of Geophysical Research-Oceans 119, 8438-8453, doi: 10.1002/2014JC010323.

Frouin, R., Pinker, R. T., 1995. Estimating Photosynthetically Active Radiation (PAR) at the earth's surface from satellite observations. Remote Sensing of Environment 51, 98-107, doi: 10.1016/0034-4257(94)00068-X.

Hama, T., Shin, K. H., Handa, N., 1997. Spatial Variability in the Primary Productivity in the East China Sea and Its Adjacent Waters. Journal of Oceanography 53, 41-51, doi: 10.1007/BF02700748.

Jean, M., 1999. Astronomical algorithms, 2nd ed. Willmann-Bell, USA.

Kahru, M., Brotas, V., Manzano-Sarabia, M., Mitchell, B. G., 2011. Are phytoplankton blooms occurring earlier in the Arctic? Global Change Biology 17, 1733-1739, doi: 10.1111/j.1365-2486.2010.02312.x.

Kim, S.T., 2012. A review of the Sea of Okhotsk ecosystem response to the climate with special emphasis on fish populations. ICES Journal of Marine Science 69, 1123-1133, doi: 10.1093/icesjms/fss107. 
Kim, T. H., Lee, Y. W., Kim, G. B., 2010. Hydrographically mediated patterns of photosynthetic pigments in the East/Japan Sea: Low N:P ratios and cyanobacterial dominance. Journal of Marine Systems 82, 72-79, doi:10.1016/j.jmarsys.2010.03.005.

Koeller, P., Fuentes-Yaco, C., Platt, T., Sathyendranath, S., Richards, A., Ouellet, P., Orr, D., Skuladottir, U., Wieland, K., Savard, L., Aschan, M., 2009. Basin-Scale Coherence in Phenology of Shrimps and Phytoplankton in the North Atlantic Ocean. Science 324, 791-793, doi: 10.1126/science.1170987.

Long, S. P., Humphries, S., Falkowski, P. G., 1994. Photoinhibition of photosynthesis in nature, Annu. Rev. Plant Physial. 45, 633-662, doi: 10.1146/annurev.pp.45.060194.003221

Longhurst, A. R., 1995. Seasonal cycles of pelagic production and consumption. Progress in Oceanography 36, 77-167, doi: 10.1016/0079-6611(95)00015-1.

Marra, J., 1978. Effect of Short-Term Variations in Light Intensity on Photosynthesis of a Marine Phytoplankter: A Laboratory Simulation Study. Marine Biology 46, 191-202, doi: 10.1007/BF00390680.

McClain, C. R., Meister, G., 2012. Mission Requirements for Future Ocean-Colour Sensors, Reports of the International Ocean-Colour Coordinating Group, No. 13, IOCCG, Dartmouth, Canada.

Morel, A. 1991. Light and marine photosynthesis: A spectral model with geochemical and climatological implications. Progress in Oceanography 26, 263-306, doi: 10.1016/0079-6611(91)90004-6.

Nicklisch, A., Shatwell, T., Köhler, J., 2008. Analysis and modelling of the interactive effects of temperature and light on phytoplankton growth and relevance for the spring bloom. Journal of Plankton Research 30, 75-91, doi: 10.1093/plankt/fbm099.

Obata, A., Ishizaka, J., Endoh, M., 1996. Global verification of critical depth theory for phytoplankton bloom with climatological in situ temperature and satellite ocean color data. Journal of Geophysical Research-Oceans 101, 20657-20667, doi: 10.1029/96JC01734.

Platt, T., Gallegos, C. L., Harrison, W. G., 1980. Photoinhibition of photosynthesis in natural assemblages of marine-phytoplankton. Journal of marine research 38, 687-701

Platt, T., Sathyendranath, S., White III, G. N., Fuentes-Yaco, C., Zhai, L., Devred, E., Tang, C., 2009. Diagnostic Properties of Phytoplankton Time Series from Remote Sensing. Estuaries and Coasts 33, 428-439, doi: 10.1007/s12237-009-9161-0.

Racault, M. F., Quéréb, C. L., Buitenhuisb, E., Sathyendranatha, S., Platt, T., 2012. Phytoplankton phenology in the global ocean. Ecological Indicators 14, 152-163, doi: 10.1016/j.ecolind.2011.07.010.

Riley, G. A., 1957. Phytoplankton of the North Central Sargasso Sea. Limnology and Oceanography 2, 252-270, doi: 10.1002/lno.1957.2.3.0252.

Shang, S. L., Li, L., Li, J., Li, Y. H., Lin, G., Sun, J., 2012. Phytoplankton bloom during the northeast monsoon in the Luzon Strait bordering the Kuroshio. Remote Sensing of Environment 124, 38-48, doi:10.1016/j.rse.2012.04.022.

Sherman, K., Hempel, G., 2009. The UNEP Large Marine Ecosystem Report: A perspective on changing conditions in LMEs of the world's Regional Seas. Nairobi, Kenya. 
Siegel, D. A., Doney, S. C., Yoder, J. A., 2002. The North Atlantic Spring Phytoplankton Bloom and Sverdrup's Critical Depth Hypothesis. Science 296, 730-733. doi: 10.1126/science.1069174.

Smetacek, V., Passow, U., 1990. Spring bloom initiation and sverdrup critical-depth model. Limnology and Oceanography 35, 228-234, doi: 10.4319/lo.1990.35.1.0228.

Sugisaki, H., Nonaka, M., Ishizaki, S., Hidaka, K., Kameda, T., Hirota, Y., Oozeki, Y., Kubota, H., Takasuka, A., 2010. Status and trends of the Kuroshio region, 2003-2008, in: McKinnell, S.M., Dagg, M.J. (Eds.), Marine Ecosystems of the North Pacific Ocean, 2003-2008. PICES Special Publication 4, pp. 330-359.

Tang, D. L., Ni, I. H., Kester, D. R., Muller-Karger, F. E., 1999. Remote Sensing Observations of Winter Phytoplankton Blooms Southwest of the Luzon Strait in the South China Sea. Marine ecology progress series 191, 43-51, doi: 10.3354/meps191043.

Taylor, J. R., Ferrari, R., 2011. Shutdown of turbulent convection as a new criterion for the onset of spring phytoplankton blooms. Limnology and Oceanography 56, 2293-2307, doi: 10.4319/lo.2011.56.6.2293.

Thomalla, S. J., Fauchereau, N., Swart, S., Monteiro, P. M. S., 2011. Regional scale characteristics of the seasonal cycle of chlorophyll in the Southern Ocean. Biogeosciences 8, 2849-2866, doi: 10.5194/bg-8-2849-2011.

Winder, M., Sommer, U., 2012. Phytoplankton response to a changing climate. Hydrobiologia 698, 5-16, doi: 10.1007/s10750-012-1149-2.

Yamada, K., Ishizaka, J., Nagata, H., 2005. Spatial and Temporal Variability of Satellite Primary Production in the Japan Sea from 1998 to 2002. Journal of Oceanography 61, 857- 869, doi: 10.1007/s10872-006-0005-2.

Yoder, J. A., Kennelly, M. A., 2003. Seasonal and ENSO variability in global ocean phytoplankton chlorophyll derived from 4 years of SeaWiFS measurements. Global Biogeochemical Cycles 17, 1-13, doi: 10.1029/2002GB001942.

Zakharkov, S. P., Selina, M. S., Vanin, N. S., Shtraikhert, E. A., Biebov, N., 2007. Phytoplankton characteristics and hydrological conditions in the western part of the Sea of Okhotsk in the spring of 1999 and 2000 based on expeditionary and satellite data. Oceanology 47, 519-530, doi: 10.1134/S0001437007040091.

Zhai, H. C., Ning, X. R., Tang, X. X., Hao, Q., Le, F. F., Qiao, J., 2011. Phytoplankton pigment patterns and community composition in the northern South China Sea during winter. Chinese Journal of Oceanology and Limnology 29, 233-245, doi: 10.1007/s00343-011-0111-x.

Zhai L., Platt, T., Tang, C., Sathyendranath, S., Walls, R. H., 2011. Phytoplankton phenology on the Scotian Shelf. ICES Journal of Marine Science 68, 781-791, doi: 10.1093/icesjms/fsq175. 